\title{
Decreased functional capacity and muscle strength in elderly women with metabolic syndrome
}

This article was published in the following Dove Press journal:

Clinical Interventions in Aging

8 October 2013

Number of times this article has been viewed

\author{
Denis Cesar Leite Vieira' \\ Ramires Alsamir Tibana' \\ Vitor Tajra' \\ Dahan da Cunha \\ Nascimento' \\ Darlan Lopes de Farias' \\ Alessandro de Oliveira \\ Silva' \\ Tatiane Gomes Teixeira' \\ Romulo Maia Carlos \\ Fonseca ${ }^{2}$ \\ Ricardo Jacó de Oliveira ${ }^{2}$ \\ Felipe Augusto dos Santos \\ Mendes ${ }^{2}$ \\ Wagner Rodrigues Martins ${ }^{2}$ \\ Silvana Schwerz Funghetto ${ }^{2}$ \\ Margo Gomes de Oliveira \\ Karnikowski \\ James Wilfred Navalta ${ }^{3}$ \\ Jonato Prestes' \\ 'Graduate Program on Physical \\ Education, Catholic University of \\ Brasilia, Brasilia, Brazil; ${ }^{2}$ University \\ of Brasilia, UnB, Brasilia, Brazil; \\ ${ }^{3}$ Department of Kinesiology and \\ Nutrition Sciences of the University \\ of Nevada, Las Vegas, NV, USA
}

Correspondence: Jonato Prestes Graduate Program on Physical Education, Catholic University of Brasilia, Brasilia,

Brazil, QS 07, Lote 0I, EPTC - Bloco G,

71966-700, Aguas Claras,

Taguatinga, DF, Brazil

Tel +556l 33569350

Email jonatop@gmail.com
Purpose: To compare the metabolic parameters, flexibility, muscle strength, functional capacity, and lower limb muscle power of elderly women with and without the metabolic syndrome (MetS).

Methods: This cross-sectional study included 28 older women divided into two groups: with the MetS $\left(\mathrm{n}=14 ; 67.3 \pm 5.5\right.$ years; $\left.67.5 \pm 16.7 \mathrm{~kg} ; 1.45 \pm 0.35 \mathrm{~m} ; 28.0 \pm 7.6 \mathrm{~kg} / \mathrm{m}^{2}\right)$, and without the MetS ( $\mathrm{n}=14 ; 68.7 \pm 5.3$ years; $58.2 \pm 9.9 \mathrm{~kg} ; 1.55 \pm 0.10 \mathrm{~m} ; 24.3 \pm 3.8 \mathrm{~kg} / \mathrm{m}^{2}$ ). Body composition was evaluated by dual-energy X-ray absorptiometry and dynamic muscle strength was assessed by one-maximum repetition (1RM) tests in leg press, bench press and biceps curl exercises. Six-minute walk test, Timed Up and Go (TUG); 30-second sitting-rising; arm curl using a 2-kg dumbbell, sit-and-reach (flexibility), and vertical jump tests were performed.

Results: There was no difference between groups regarding age $(P=0.49)$, height $(P=0.46)$, body fat $(\%)(P=0.19)$, systolic $(P=0.64)$, diastolic $(P=0.41)$ and mean blood pressure $(P=0.86), 30$-second sitting-rising $(P=0.57), 30$-s arm curl $(P=0.73)$, leg press $1 \mathrm{RM}$ $(P=0.51)$, bench press $1 \mathrm{RM}(P=0.77)$, and biceps curl 1RM $(P=0.85)$. However, women without the MetS presented lower body mass $(P=0.001)$, body mass index (BMI) $(P=0.0001)$, waist circumference $(P=0.02)$, waist-to-height ratio $(P=0.02)$, fat body mass $(\mathrm{kg})(P=0.05)$, lean body mass $(\mathrm{kg})(P=0.02)$, blood glucose $(P=0.05)$, triglycerides $(P=0.03), Z$-score for the MetS $(P=0.05)$, higher high-density lipoprotein-cholesterol (HDL-C) $(P=0.002)$, better performance on TUG $(P=0.01)$, flexibility $(P=0.03)$, six-minute walk test $(P=0.04)$, vertical jump $(P=0.05)$ and relative muscle strength for leg press $(P=0.03)$, bench press $(P=0.04)$ and biceps curl $(P=0.002)$ exercises as compared to women with the MetS.

Conclusion: Elderly women with the MetS have higher metabolic risk profile and lower functional capacity, muscle strength, lower limb power and flexibility as compared to women without the MetS. The evaluation of functional capacity may help to determine the degree of physical decline in older persons with the MetS, while exercise interventions should be encouraged.

Keywords: metabolic syndrome, functional capacity, muscle performance, aging

\section{Introduction}

The term metabolic syndrome (MetS) describes a collection of risk factors that includes obesity, insulin resistance, hypertension, and an abnormal lipid profile. These risk factors are associated with an increased risk of gastrointestinal cancer, diabetes mellitus, cardiovascular disease, ${ }^{3}$ and premature mortality. ${ }^{1-5}$ The prevalence of the MetS has increased worldwide, in parallel with the increasing prevalence of obesity; data have revealed an alarming 32.0\% prevalence of the MetS in the central region of Brazil. ${ }^{6}$ The prevalence of most individual consequences of the MetS increases with age. For example, in the third National Health and Nutrition Examination Survey (NHANES III) 
performed in the United States, the prevalence of the MetS was $6.7 \%$ in persons 20 to 29 years old, $43.5 \%$ in those 60 to 69 years old, and $42.0 \%$ in individuals 70 years or older. ${ }^{7}$

Importantly, the decline in physical function that occurs with aging often represents the early stage of a continuous process that leads to disability and other important adverse outcomes. The decline in functional capacity is associated with decreases in levels of flexibility, performance of activities of daily living, muscle power, and lower and upper limb strength. Simple objective measures of physical performance (walking speed, sitting to rising, and standing balance time) and muscle strength have been used to predict the onset of disability in older community-dwelling populations. ${ }^{8}$ In this sense, an understanding of the factors that contribute to increased disability and functional declines in an aging population has an important public health value.

Studies have linked the MetS to physical decline in older persons. ${ }^{9,10}$ Penninx et $\mathrm{al}^{9}$ revealed that older persons with the MetS displayed a 50\% greater chance of developing mobility limitations compared with those without the MetS. Similarly, Everson-Rose et al demonstrated that elderly men with the MetS had an approximately 1-point lower performance score and a $0.04 \mathrm{~m} / \mathrm{s}$ slower walking speed than men without the MetS. ${ }^{10}$ Moreover, several investigations in the current literature have shown that individuals with the MetS display lower muscle strength and cardiorespiratory fitness. ${ }^{11-14}$ Additionally, it has been shown that elderly women with the MetS presented lower high-density lipoprotein (HDL), higher glucose, creatine kinase, C-reactive protein, and triglycerides as compared with elderly women without the MetS, reinforcing the findings of metabolic disturbance in older people with the MetS. ${ }^{13}$ However, to the best of our knowledge, no previous study has been designed to compare the physical performance and metabolic parameters in elderly women with and without the MetS.

The aim of the present study was to compare the metabolic parameters, flexibility, muscle strength, functional capacity and lower limb muscle power between elderly women with and without the MetS. The initial hypothesis was that women with the MetS could present more metabolic risk factors and reduced physical capacity as compared with those without the MetS.

\section{Methods}

\section{Participants}

Participants were recruited on a voluntary basis from the Taguatinga community through posters and lectures about the study. Forty sedentary elderly women older than 60 years were selected by convenience and were not necessarily representative of the Brazilian female population. They were considered sedentary by accruing less than 2 hours per week of physical activity during the past year. Participants completed a recall form and physical activity questionnaire and were subjected to anthropometric measures. Twelve subjects were excluded from the analysis because of malignancy, immunosuppressive therapy, known inflammatory disease (eg, arthritis, inflammatory bowel disease, psoriasis), acute infection, or invasive procedures (eg, surgery, catheterization) during the last 6 months as evaluated in the medical history questionnaire. Following these exclusions, the study group comprised 28 older women assigned into two groups: with the MetS $(\mathrm{n}=14 ; 67.3 \pm 5.5$ years; $67.5 \pm 16.7 \mathrm{~kg} ; 1.45 \pm 0.35 \mathrm{~m}$; $\left.28.0 \pm 7.6 \mathrm{~kg} / \mathrm{m}^{2}\right)$, and without the MetS $(\mathrm{n}=14$; $68.7 \pm 5.3$ years; $\left.58.2 \pm 9.9 \mathrm{~kg} ; 1.55 \pm 0.10 \mathrm{~m} ; 24.3 \pm 3.8 \mathrm{~kg} / \mathrm{m}^{2}\right)$. The MetS was defined according to the criteria of the National Cholesterol Education Program's Adult Treatment Panel III $\left(\right.$ NCEP-ATP III) ${ }^{15}$ : waist circumference $($ WC) $>88 \mathrm{~cm}$; triglycerides $>150 \mathrm{mg} / \mathrm{dL}$; high-density lipoproteincholesterol $(\mathrm{HDL}-\mathrm{C})<50 \mathrm{mg} / \mathrm{dL}$; fasting glucose $>110 \mathrm{mg} / \mathrm{dL}$; systolic blood pressure $(\mathrm{SBP})>130 \mathrm{mmHg}$; or diastolic blood pressure (DBP) $>85 \mathrm{mmHg}$. A Z-score was calculated for each variable using individual subject data following the ATP III criteria. The equation used to calculate the MetS Z-score was as follows: $Z$-score $=([50-\mathrm{HDL}-\mathrm{C}$ $\mathrm{mg} / \mathrm{dL}] / 11.8)+([$ triglycerides $\mathrm{mg} / \mathrm{dL}-150] / 66.2)+([$ fasting blood glucose $\mathrm{mg} / \mathrm{dL}-110] / 10.4)+([\mathrm{WC} \mathrm{cm}-$ $88] / 9.2)+([$ mean arterial pressure $\mathrm{mmHg}-100] / 8.7) / 100 .{ }^{16}$ The Catholic University of Brasilia Ethics Committee for Human Research approved the methods of the present study, and all participants signed an informed consent document.

\section{Blood pressure measurement}

SBP, DBP, and mean blood pressure (MBP) were measured with an oscillometric device (BP 3AC1-1 PC; Microlife AG, Widnau, Switzerland) according to the recommendations of the Brazilian Society of Cardiology. ${ }^{17}$ The cuff size was adapted to the circumference of the arm of each participant according to the manufacturer's recommendations. SBP and DBP values were used to determine MBP according to the following equation: $\mathrm{MBP}=\mathrm{DBP}+([\mathrm{SBP}-\mathrm{DBP}] / 3)$.

\section{Anthropometric measures}

The body mass measurement was taken with the individual wearing light clothes and bare feet, using digital scales (W110H, Welmy, São Paulo, Brazil) with a capacity of 
$150 \mathrm{~kg}$, and 100-gram divisions. Height was measured by a wall stadiometer (Sanny, American Medical do Brasil, São Paulo, Brazil), with capacity of 2,200 mm and 1-mm divisions. Height and body mass were measured for the calculation of the body mass index (BMI). The waist circumference was obtained using a nonelastic tape; measurements were obtained in triplicate and then averaged. Waist circumference was measured at the midpoint between the lower rib margin and the iliac crest. Percent body fat and lean body mass were determined by dual-energy X-ray absorptiometry (General Electric-GE model 8548 BX1 L, Lunar DPX type, Encore 2005 software; Madison, WI, USA).

\section{Functional capacity tests}

Physical function was examined using a battery of tests as follows. A 30-second chair-stand test that measured the number of times that a subject was able to stand from a standard chair and sit down again during 30 seconds was evaluated. ${ }^{18}$ The 30 -second arm curl test measured upperbody muscle function and was assessed by the number of arm curl repetitions performed with a 2-kg dumbbell during 30 seconds. ${ }^{18}$ A Timed Up and Go (TUG) test was used to determine the amount of time required for the subject to rise from a standard armchair, walk 3 meters away, turn, return, and sit down again. ${ }^{18}$

\section{Flexibility}

The sit-and-reach test was used to evaluate flexibility as previously described. ${ }^{19}$ Briefly, individuals sat on the floor with legs stretched out straight ahead while the soles of the feet were placed flat against the box with knees locked and pressed. With the palms facing downward and the hands on top of each other, the subjects were advised to reach forward along the measuring line as far as possible and to hold that position for 1 to 2 seconds while the distance was being recorded.

\section{Six-minute walk test}

The six-minute walk test has been used as a one-time measure of functional status and has a high correlation with peak oxygen uptake. ${ }^{20}$ The test was performed as recommended by the American Thoracic Society. ${ }^{20}$ The six-minute walk test was performed in a 30-meter long indoor hallway free of obstacles. The length of the corridor was marked every 1 meter. Participants were instructed to walk at a self-selected regular pace to cover as much distance as they were able during the allotted time. If necessary, slowing down and stopping to rest were allowed. Feedback regarding the elapsed time was provided at the end of each minute, and standardized encouragement was expressed by statements such as "you are doing well, keep it up" and "do your best." 21

\section{One-repetition maximum muscle strength test (IRM)}

All participants completed a familiarization protocol on the equipment before the test procedures took place. ${ }^{22}$ During this period, standard instructions and explanations about the procedures of the test protocols and the proper execution of exercise technique were given to participants. To enhance reliability, testing procedures were administered by the same investigator. Two tests on two different days with a minimum of 48 hours of rest were conducted (test-retest). The 1RM test was used to determine the dynamic muscle strength of upper and lower limbs using conventional isoinertial weight training machines (Righetto, São Paulo, Brazil). The heaviest weight that can be lifted once is the most common measure of weight lifting strength. ${ }^{22}$

The 1RM protocol was conducted according to the method of Brown and Weir, ${ }^{23}$ including load standardization, exercise range of motion, and lifting technique during the performance of each exercise. Prior to the 1RM tests, two light warm-up sets were interspersed with 2-minute rest periods. Then, the participants had up to five attempts to achieve the $1 \mathrm{RM}$ load (ie, maximum weight that could be lifted once with proper technique), with a 5-minute interval between attempts and 10-minute interval between exercises. The tests were conducted for leg press, bench press, and biceps-curl exercises. The strength tests were performed on two different days interspaced by a 48 to 72 hour period, allowing for the determination of test-retest reliability (ie, intraclass coefficient) for both groups, $r=0.97, r=0.99, r=0.99$ for leg press, bench press, and biceps-curl, respectively. Both testing sessions took place between $2 \mathrm{pm}$ to $3 \mathrm{pm}$ after lunch and under a controlled standardized temperature.

Relative muscle strength was determined by the division of absolute values by body mass. Moreover, relative muscle strength has been recommended as a more accurate method to compare muscle strength between individuals of differing physical condition. ${ }^{24}$

\section{Vertical jump test}

A contact mat (Pro Model; Cefise Sports Biotechnology, Nova Odessa, Brazil) was connected to a computer running Windows XP. The height of the vertical jump was calculated using JUMPING PRO software (Sports Timing Systems, http://www.sportstimingsystems.co.uk/) from the flight time measured in each attempt. Individuals stepped on the contact 
mat and put their feet in a lateral position aligned with their hips, hands around the waist. ${ }^{25}$ Volunteers were asked to perform four attempts of a countermovement vertical jump with rest intervals of 40 seconds between trials. This procedure was repeated 5 to 7 days after the initial testing period. Individuals were asked to perform a maximal countermovement jump to the greatest height possible after a signal from the evaluator. The joint angle of knee flexion was self-selected by the volunteers. Additionally, participants were advised to avoid knee flexion during the landing phase of the movement. This procedure could overestimate the height of the jump with an artificial increment of flight time. If this maneuver occurred, the jump was not validated, and the individual was required to perform another attempt. Both testing sessions took place between $2 \mathrm{pm}$ to $3 \mathrm{pm}$ after lunch and under a controlled standardized temperature.

\section{Biochemical measures}

Individuals reported to the laboratory between 8 am to 10 am after an overnight fast, for blood withdrawal from the antecubital vein. Plasmatic triglycerides and glucose levels were measured by enzymatic cholesterol esterase/peroxidase (CHOP-POD) and hexokinase methods, respectively. Highdensity lipoprotein was measured by the Automation Method
(Autohumalyzer, HUMAN Diagnostics GMBH, Wiesbaden, Germany).

\section{Statistical analysis}

The significance level for all studied variables was fixed at $P \leq 0.05$. Initially a descriptive analysis of the variables was carried out with central trend and dispersion data. Next, the Kolmogorov-Smirnov test and Levene's test were conducted to assess data normalcy and homoscedasticity, respectively. Individuals were separated as having $(n=14)$ or not having the MetS $(n=14)$. Differences between groups for anthropometric data, body composition parameters, blood pressure, biochemical, and physical function were evaluated by the unpaired Student's $t$-test. In addition, the correlation between the MetS $Z$-score and physical performance parameters was evaluated by the Pearson's correlation coefficient. Correlation coefficient values between \pm 0.1 and $\pm 0.3, \pm 0.4$ and \pm 0.6 , and $>0.7$ were considered weak, moderate, and strong, respectively. Data were analyzed using SPSS $^{\circledR}$ version 19 (IBM Corporation, Armonk, NY, USA).

\section{Results}

Table 1 presents the anthropometric, biochemical, and hemodynamic variables of the groups with and without the MetS.

Table I Anthropometric, biochemical and hemodynamic parameters of the study population

\begin{tabular}{|c|c|c|c|c|}
\hline Variable & $\begin{array}{l}\text { MetS } \\
(n=14)\end{array}$ & $\begin{array}{l}\text { Without MetS } \\
(n=14)\end{array}$ & $\begin{array}{l}\text { Difference between } \\
\text { means }(95 \% \mathrm{Cl})\end{array}$ & $P$-value \\
\hline \multicolumn{5}{|l|}{ Anthropometric parameters } \\
\hline Age (years) & $67.3 \pm 5.5$ & $68.7 \pm 5.3$ & I.42 (-2.8; 5.6) & 0.49 \\
\hline Body mass (kg) & $65.5 \pm 16.7^{*}$ & $58.2 \pm 9.9$ & $-12.9(-20.2 ;-5.6)$ & 0.001 \\
\hline Height (m) & $1.45 \pm 0.35$ & $1.55 \pm 0.10$ & $0.02(-0.04 ;-0.08)$ & 0.46 \\
\hline Waist circumference $(\mathrm{cm})$ & $82.7 \pm 21.3^{*}$ & $79.0 \pm 8.6$ & $-9.3(-17.2 ;-1.5)$ & 0.02 \\
\hline Waist-to-height ratio & $0.54 \pm 0.15^{*}$ & $0.51 \pm 0.06$ & $-0.07(-0.12 ;-0.01)$ & 0.02 \\
\hline \multicolumn{5}{|l|}{ Body composition } \\
\hline Body mass index $\left(\mathrm{kg} / \mathrm{m}^{2}\right)$ & $28.0 \pm 7.6^{*}$ & $24.3 \pm 3.8$ & $-6.38(-9.5 ;-3.3)$ & 0.0001 \\
\hline Body fat (\%) & $42.6 \pm 5.1$ & $39.3 \pm 6.8$ & $-3.24(-8.3 ; 1.8)$ & 0.19 \\
\hline Fat body mass (kg) & $28.6 \pm 7.1^{*}$ & $22.7 \pm 7.1$ & $-5.97(-12.0 ; 0.07)$ & 0.05 \\
\hline Lean body mass (kg) & $37.6 \pm 4.6^{*}$ & $33.8 \pm 2.8$ & $-3.85(-7.15 ;-0.54)$ & 0.02 \\
\hline Leg lean body mass (kg) & $11.5 \pm 1.6$ & $10.5 \pm 1.2$ & $-0.99(-2.19 ; 0.21)$ & 0.10 \\
\hline Relative leg lean body mass & $0.16 \pm 0.02 *$ & $0.18 \pm 0.02$ & $0.02(-0.01 ;-0.04)$ & 0.01 \\
\hline \multicolumn{5}{|l|}{ Biochemical parameters } \\
\hline Glucose (mg/dL) & $93.2 \pm 28.0^{*}$ & $90.1 \pm 9.6$ & $-10.2(-22.0 ; 1.6)$ & 0.05 \\
\hline Triglycerides (mg/dL) & $185.4 \pm 95.3^{*}$ & $137.4 \pm 66.7$ & $-69.3(-132.6 ;-5.9)$ & 0.03 \\
\hline $\mathrm{HDL}-\mathrm{C}(\mathrm{mg} / \mathrm{dL})$ & $40.6 \pm 10.2^{*}$ & $50.6 \pm 7.7$ & $9.1(3.7 ; 14.6)$ & 0.002 \\
\hline Z-score of MetS & $1.29 \pm 0.06 *$ & $1.25 \pm 0.03$ & $-0.04(-0.07 ; 0.01)$ & 0.05 \\
\hline \multicolumn{5}{|l|}{ Hemodynamic variables } \\
\hline Systolic blood pressure $(\mathrm{mmHg})$ & $117.7 \pm 29.7$ & $121.8 \pm 7.7$ & $-1.78(-9.7 ; 6.1)$ & 0.64 \\
\hline Diastolic blood pressure $(\mathrm{mmHg})$ & $74.0 \pm 18.5$ & $79.3 \pm 2.7$ & $\mathrm{I} .42(-2.1 ; 4.9)$ & $0.4 \mathrm{I}$ \\
\hline Mean blood pressure $(\mathrm{mmHg})$ & $88.5 \pm 22.2 S$ & $93.5 \pm 3.2$ & $0.35(-3.8 ; 4.6)$ & 0.86 \\
\hline
\end{tabular}

Note: *Significant difference between groups.

Abbreviations: MetS, metabolic syndrome; n, number of subjects; $\mathrm{Cl}$, confidence interval; HDL-C, high-density lipoprotein-cholesterol. 
There was no difference between groups with respect to age $(P=0.49)$, height $(P=0.46)$, body fat percentage $(P=0.19)$, leg lean body mass $(P=0.10)$, SBP $(P=0.64)$, DBP $(P=0.41)$, and MBP $(P=0.86)$. However, women without the MetS had lower body mass $(P=0.001)$, BMI $(P=0.0001)$, WC $(P=0.02)$, waist-to-height ratio $(P=0.02)$, fat body mass $(P=0.05)$, lean body mass $(P=0.02)$, blood glucose $(P=0.05)$, triglycerides $(P=0.03)$, and $Z$-score of MetS $(P=0.05)$, higher HDL-C $(P=0.002)$, and relative leg lean body mass $(P=0.01)$ when compared with women with the MetS.

Functional performance and muscle strength tests are presented in Table 2. There was no difference between groups for 30-second chair rise $(P=0.57)$, 30-second arm curl $(P=0.73)$, leg press 1RM $(P=0.51)$, bench press $1 \mathrm{RM}$ $(P=0.77)$, and biceps curl 1RM $(P=0.85)$. However, women without the MetS presented a greater performance on TUG $(P=0.01)$, sit-and-reach $(P=0.03)$, the six-minute walk test $(P=0.04)$, vertical jump $(P=0.05)$ and relative muscle strength on the leg press $(P=0.03)$, bench press $(P=0.04)$ and biceps curl $(P=0.002)$ exercises (Figures 1 and 2$)$.

Correlations among the variables of the study are summarized on Figure 3 and Figure 4. There was a moderate correlation of $Z$-score of MetS with TUG test $(P=0.001$; $r=0.55)$ and with relative leg lean body mass $(P=0.01$; $r=-0.46)$. Moreover, there were moderate negative correlations for risk factors of the MetS with relative leg lean body mass $(P=0.001 ; r=-0.55)$, six-minute walk test $(P=0.01$; $r=-0.44)$ and vertical jump $(P=0.01 ; r=-0.44)$. Thus, the higher were the risk factors, the lower were muscle capacity and relative lower limb lean mass.

\section{Discussion}

The aim of this study was to compare the metabolic parameters, flexibility, functional capacity, lower limb power and muscle strength of older women with and without the MetS. Confirming the initial hypothesis, elderly women without the MetS had greater functional capacity, muscle flexibility, lower limb power, muscle strength, and fewer metabolic risk factors as compared with elderly women with the MetS. Additionally, the $Z$-score of MetS and risk factors of MetS were correlated with functional capacity tests and relative leg lean mass.

Cardiometabolic parameters of MetS can be associated with several diseases and mortality, and low HDL-C can be correlated with mortality in geriatric individuals. ${ }^{26,27}$ Cabrera et $\mathrm{al}^{28}$ reported, in a 12 -year longitudinal study with 800 individuals, that hypertension, diabetes, hypertriglyceridemia, and the MetS increased the risk of cardiovascular events. Additionally, Cabrera et $\mathrm{al}^{29}$ conducted a follow-up study for 6.6 years in 516 women and demonstrated that there are positive associations between the MetS and cardiovascular diseases independent of age and previous cardiovascular disease. Thus, high cardiometabolic parameters can represent a risk to health.

Evidence also suggests that high cardiometabolic parameters of the MetS are related to physical capacity and mobility in elderly individuals. ${ }^{9,10,30}$ In the present study, women with the MetS presented lower functional capacity and muscle strength when compared to women without the MetS. Similarly, Penninx et al reported in a follow-up study of 4.5 years with elderly women and men that there was a strong association between mobility limitations and the number of

Table 2 Functional capacity, flexibility and muscle strength tests of the study population

\begin{tabular}{|c|c|c|c|c|}
\hline Variable & $\begin{array}{l}\text { MetS } \\
(n=14)\end{array}$ & $\begin{array}{l}\text { Without MetS } \\
(n=14)\end{array}$ & $\begin{array}{l}\text { Difference between } \\
\text { means }(95 \% \mathrm{Cl})\end{array}$ & $P$-value \\
\hline \multicolumn{5}{|l|}{ Functional capacity } \\
\hline 30-second chair timed-stand (repetitions) & $17.6 \pm 3.2$ & $\mid 8.1 \pm 4.1$ & $-0.78(-3.6 ; 2.0)$ & 0.57 \\
\hline 30-second arm curl (repetitions) & $20.8 \pm 3.2$ & $21.7 \pm 3.6$ & $-0.42(-2.9 ; 2.1)$ & 0.73 \\
\hline Timed Up and Go (seconds) & $6.7 \pm 1.2^{*}$ & $6.2 \pm 0.9$ & $-1.05(-1.9 ;-0.2)$ & 0.017 \\
\hline Flexibility sit and reach $(\mathrm{cm})$ & $21.3 \pm 5.0^{*}$ & $26.3 \pm 5.0$ & $5.93(2.1 ; 9.7)$ & 0.03 \\
\hline Six-minute walk test $(\mathrm{m})$ & $458.4 \pm 80.1 *$ & $527.9 \pm 33.9$ & $52.3(2.1 ; 102.5)$ & 0.04 \\
\hline Vertical Jump (cm) & $9.3 \pm 2.4^{*}$ & $11.6 \pm 2.6$ & $2.56(0.45 ; 4.7)$ & 0.05 \\
\hline \multicolumn{5}{|l|}{ Muscle strength } \\
\hline Leg press (kg) & $97.3 \pm 30.4$ & $105.7 \pm 39.2$ & $8.8(-18.4 ; 36.2)$ & 0.51 \\
\hline Relative (leg press kg/body mass) & $1.44 \pm 0.40 *$ & $1.78 \pm 0.55$ & $0.4 \mathrm{I}(0.03 ; 0.78)$ & 0.03 \\
\hline Bench press $(\mathrm{kg})$ & $21.7 \pm 5.6$ & $22.4 \pm 5.1$ & $-0.59(-4.83 ; 3.6)$ & 0.77 \\
\hline Relative (bench press kg/body mass) & $0.32 \pm 0.07^{*}$ & $0.39 \pm 0.08$ & $0.6 \mathrm{I}(0.00 ; 0.12)$ & 0.04 \\
\hline Biceps curl (kg) & $14.6 \pm 3.1$ & $15.5 \pm 2.8$ & $0.22(-2.11 ; 2.55)$ & 0.85 \\
\hline Relative (biceps curl kg/body mass) & $0.21 \pm 0.04 *$ & $0.27 \pm 0.04$ & $0.05(0.02 ; 0.08)$ & 0.002 \\
\hline
\end{tabular}

Note: *Significant difference between groups.

Abbreviations: MetS, metabolic syndrome; $n$, number of subjects; $\mathrm{Cl}$, confidence interval. 

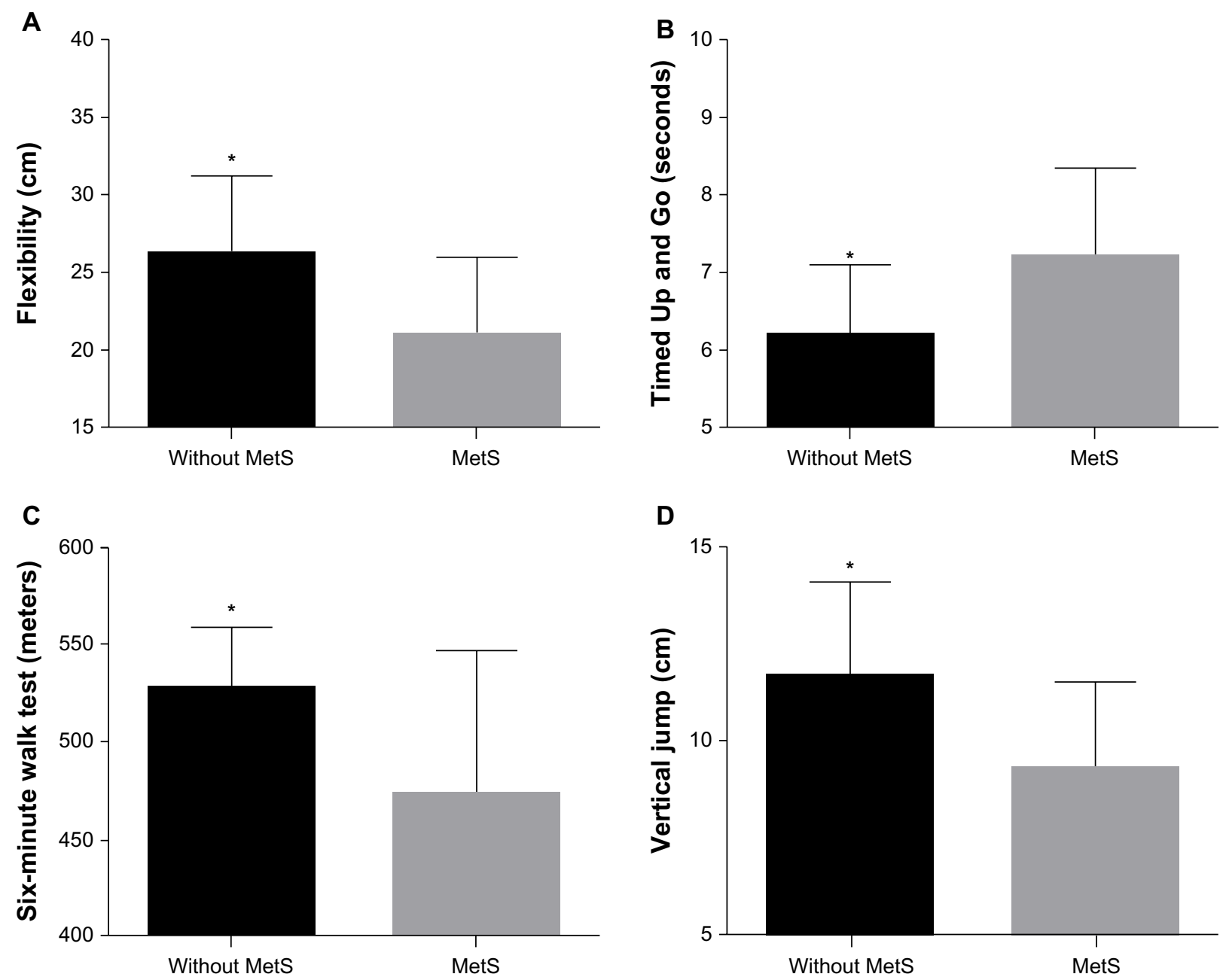

Figure I Comparison of the flexibility, functional capacity and vertical jump between elderly women with and without the metabolic syndrome.

Notes: *Statistically significant difference between women with and without the metabolic syndrome $(P<0.05)$. Panel A, sit-and-reach test; panel B, Time UP and Go test; panel C, six-minute walk test; panel D, vertical jump test.

Abbreviation: MetS, metabolic syndrome.

MetS components. In addition, elderly subjects with the MetS presented a $50 \%$ increased chance for developing mobility limitations than those without the MetS. ${ }^{9}$ Everson-Rose et al reported that high triglycerides, low HDL, hyperglycemia, and higher BMI were associated with poorer performance scores on physical capacity tests. Women without the MetS demonstrated greater performance on a gait speed test (capacity to walk $6 \mathrm{~m}$ at a normal pace as fast as possible), balance test (capacity to walk within a $20 \mathrm{~cm}$ wide path that extended over $6 \mathrm{~m}$ as fast as possible) and chair stands (ability to rise five times off the chair without using arms, as fast as possible). ${ }^{10}$

In the present study, elderly women without the MetS also presented lower body mass and BMI when compared with elderly women with the MetS. In this regard, Messier et al reported that weight loss can reduce mechanical stress on the knee-joint during walking. This relationship between weight loss and patellofemoral compressive force on the knee is $1: 4$ (ie, for every pound of weight loss there is a 4-fold reduction of mechanical stress on the knee). ${ }^{31}$ In this sense, excess body weight can be related to mechanical stress, pain, reduction of daily living activity, and consequently, the degree of physical mobility. ${ }^{31}$ BMI has also been shown to be an independent predictor of functional capacity, demonstrating an inverse association with functional capacity, which highlights the importance of weight control for preservation of physical mobility. ${ }^{32}$

Another important finding is that elderly women without the MetS showed greater relative muscle strength and muscle power. Our study is in accordance with the results of Tibana et al, which demonstrated that middle-age women without the MetS had greater relative muscle strength as assessed by handgrip strength when compared with women with MetS. ${ }^{12}$ In a cohort study, Sayer et al evaluated handgrip strength 

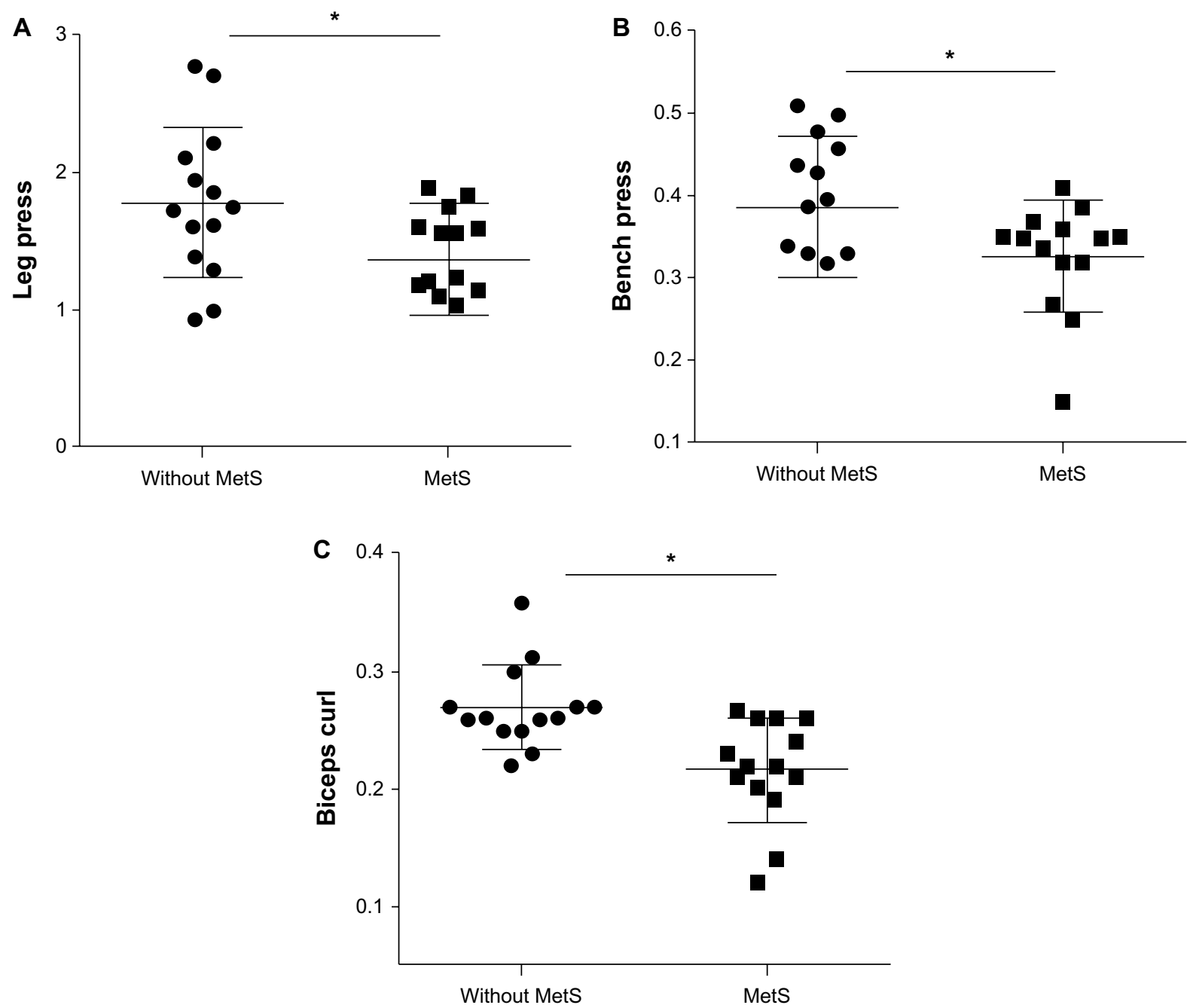

Figure 2 Comparison of relative muscle strength between elderly women with and without metabolic syndrome.

Notes: *Statistically significant difference between women with and without the metabolic syndrome $(P<0.05)$. Panel $A$, leg press relative muscle stregth; panel $B$, bench press relative muscle strength; panel $\mathrm{C}$, biceps curl relative muscle strength.

Abbreviation: MetS, metabolic syndrome.

in 2,677 men and women aged 59 to 73 years and reported that lower handgrip strength is associated with high fasting triglycerides, blood pressure, waist circumference, insulin resistance, and the MetS. ${ }^{33}$ Regarding muscle power, Sartorio et al reported that lean body mass showed a positive linear relationship with muscle power in a stair-climbing test in 1,298 obese women and men. ${ }^{34}$

Thus, muscle strength and power are import factors that contribute to functional capacity and mobility in the elderly. ${ }^{35-37}$ Hanson et al reported that changes in muscle power, muscle strength, lean body mass, and body fat are predictors of functional test performance, such as the six-minute rapid walk test, five-time chair stand, stair climb, and get up and go (similar to TUG). ${ }^{35}$ In the present study, we used the vertical jump to estimate jump height, which is a relevant and indirect measure of muscle power of the lower limbs. ${ }^{23,25}$ Regarding this, our results demonstrated that women without the MetS showed lower values of fat mass and greater values of muscle strength, vertical jump, relative leg lean mass, and physical performance in functional tests when compared with women with the MetS. These results reinforce the evaluation of muscle strength and power as an important tool for determining the degree of compromise in functional capacity for elderly individuals. Also, women with the MetS may require additional health care attention, as they present lower scores for muscle force and mobility as compared with women without the MetS.

Skeletal muscle can play an important role in functional capacity and also in cardiometabolic factors associated with the MetS, as the MetS is associated with muscle strength and power. ${ }^{38}$ Moreover, skeletal muscle has been shown to be essential for glucose and triglyceride uptake..$^{39,40}$ 

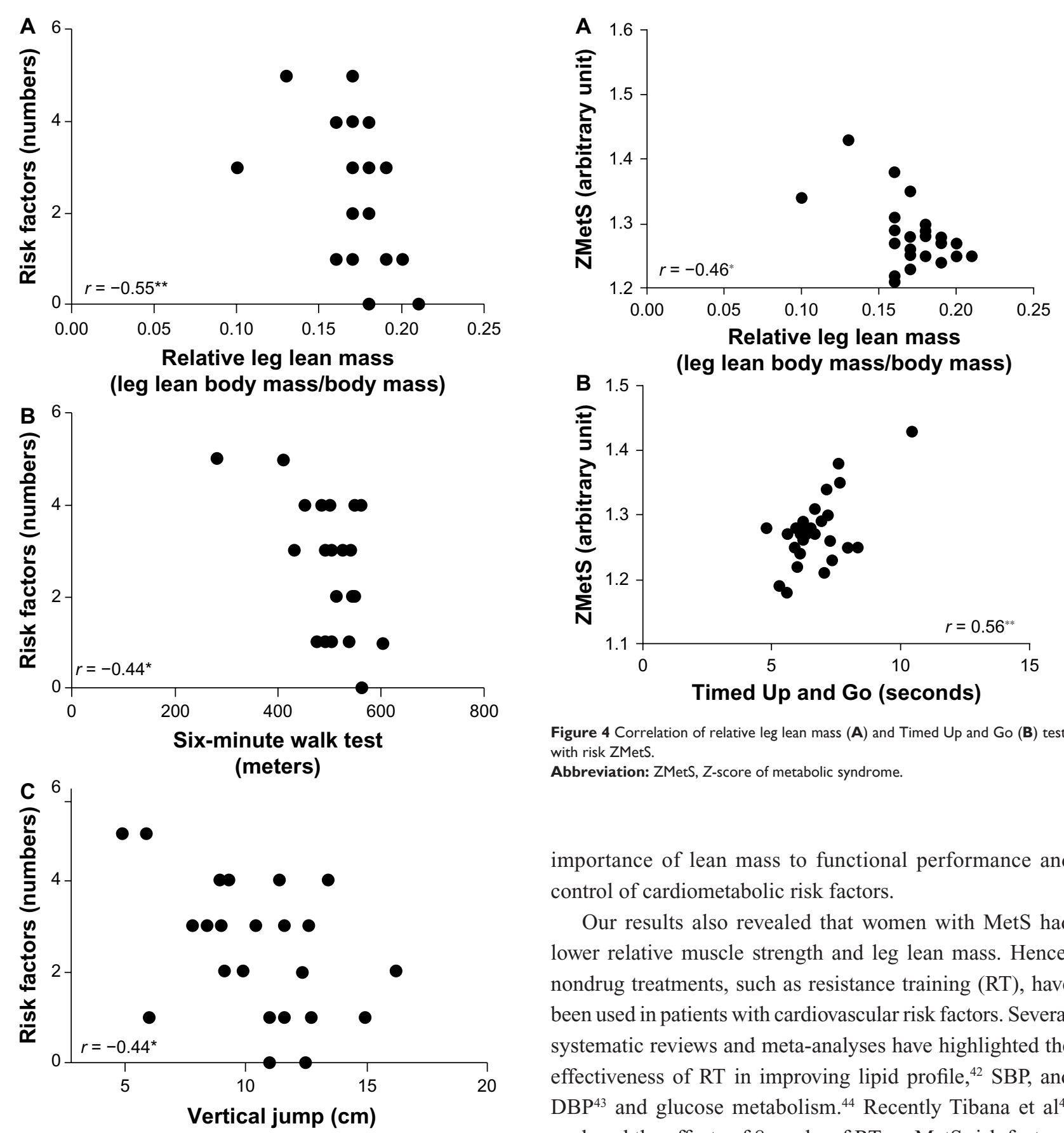

Figure 4 Correlation of relative leg lean mass $(\mathbf{A})$ and Timed Up and Go (B) tests with risk ZMetS.

Abbreviation: ZMetS, Z-score of metabolic syndrome.

importance of lean mass to functional performance and control of cardiometabolic risk factors.

Our results also revealed that women with MetS had lower relative muscle strength and leg lean mass. Hence, nondrug treatments, such as resistance training (RT), have been used in patients with cardiovascular risk factors. Several systematic reviews and meta-analyses have highlighted the effectiveness of RT in improving lipid profile, ${ }^{42}$ SBP, and $\mathrm{DBP}^{43}$ and glucose metabolism. ${ }^{44}$ Recently Tibana et $\mathrm{al}^{45}$ analyzed the effects of 8 weeks of RT on MetS risk factors,

Figure 3 Correlation of relative leg lean mass (A), six-minute walk test (B) and vertical jump (C) with number of metabolic syndrome risk factors. Notes: $* P \leq 0.05 ; * * P \leq 0.01$.

Additionally, individuals with lower leg lean mass show a greater functional limitation. ${ }^{41}$ Regarding this, women without the MetS presented greater relative leg lean mass. Moreover, there were positive correlations between relative leg lean mass and functional performance in the six-minute walk and TUG tests. In addition, negative correlations were found between relative leg lean mass with $Z$-score of MetS and the number of factors of MetS, which highlights the muscle strength, and muscle thickness in overweight/obese middle-aged women. The study revealed that chronic RT induced an increase in rectus femoris muscle thickness and muscle strength. Therefore, RT can be considered a component in a physical activity program designed to prevent and treat physical decline in patients with the MetS.

Some methodological limitations of the present study are worth mentioning. It is a cross-sectional study, with a reduced number of participants, which hinders the establishment of a cause-effect relation between the MetS, functional capacity, and relative muscle strength. Moreover, additional metabolic 
parameters and different types of muscle strength tests, such as isokinetic and isometric tests, could be included. Longitudinal and experimental studies could be required to establish this association between cardiometabolic parameters, lean body mass, muscle strength, muscle power, and functional capacity in elderly individuals with and without the MetS.

\section{Conclusion}

The present study has demonstrated that women with the MetS presented greater metabolic risk factors and less functional capacity, lower limb power, muscle strength, and relative leg lean mass. Therefore, physical activity programs with RT should be included for the prevention of physical decline in elderly women with the MetS. Moreover, the decreased muscle strength and power in elderly women with the MetS reinforces the importance of preventive programs, including exercise, in this population. Future studies should focus on correlations between physical capacity and chronic kidney diseases in elderly individuals with the MetS.

\section{Acknowledgment}

The authors thank the Conselho Nacional de Desenvolvimento Científico e Tecnológico - CNPq (483549/2011-8) and the Sistema de Gestão Estratégica da Pesquisa - SIGEP/ UCB (1683104057204027) for financial support for this research.

\section{Disclosure}

The authors declare no conflicts of interest in this work. None of the authors had financial or personal conflicts of interest with regard to this study.

\section{References}

1. Matthews CE, Sui X, LaMonte MJ, et al. Metabolic syndrome and risk of death from cancers of the digestive system. Metab. 2010;59: 1231-1239.

2. Wilson PW, D'Agostino RB, Parise H, et al. Metabolic syndrome as a precursor of cardiovascular disease and type 2 diabetes mellitus. Circulation. 2005;112:3066-3072.

3. Isomaa B, Almgren P, Tuomi T, et al. Cardiovascular morbidity and mortality associated with the metabolic syndrome. Diabetes Care. 2001;24:683-689.

4. Lakka HM, Laaksonen DE, Lakka TA, et al. The metabolic syndrome and total and cardiovascular disease mortality in middle-aged men. JAMA. 2002;4:2709-2716.

5. Sundström J, Risérus U, Byberg L, et al. Clinical value of the metabolic syndrome for long term prediction of total and cardiovascular mortality: prospective, population based cohort study. BMJ. 2006;15:878-882.

6. Dutra ES, de Carvalho KM, Miyazaki E, et al. Metabolic syndrome in central Brazil: prevalence and correlates in the adult population. Diabetol Metab Syndr. 2012;4:20.

7. Ford ES, Giles WH, Dietz WH. Prevalence of the metabolic syndrome among US adults: findings from the third National Health and Nutrition Examination Survey. JAMA. 2002;16:356-359.
8. Hardy R, Cooper R, Aihie Sayer A, et al. Body mass index, muscle strength and physical performance in older adults from eight cohort studies: the HALCyon programme. PLoS One. 2013;8:e56483.

9. Penninx BW, Nicklas BJ, Newman AB, et al. Metabolic syndrome and physical decline in older persons: results from the Health, Aging and Body composition study. J Gerontol A Biol Sci Med Sci. 2009;64: 96-102.

10. Everson-Rose SA, Paudel M, Taylor BC, et al. Osteoporotic Fractures in Men Research Group. Metabolic syndrome and physical performance in elderly men: the osteoporotic fractures in men study. J Am Geriatr Soc. 2011;59:1376-1384.

11. Jurca R, Lamonte MJ, Church TS, et al. Associations of muscle strength and fitness with metabolic syndrome in men. Med Sci Sports Exerc. 2004;36:1301-1307.

12. Tibana RA, Tajra V, Cesar D, et al. Comparação da força muscular entre mulheres brasileiras com e sem síndrome metabólica. [Comparison of muscle strength between Brazilian women with and without metabolic syndrome] ConScientiae Saúde. 2011;10:708-714 Portugese.

13. Farias DL, Tibana RA, Teixeira TG, et al. Elderly women with metabolic syndrome presented higher cardiovascular risk and lower relative muscle strength. Einstein. 2013;1:174-179.

14. Earnest CP, Artero EG, Sui X, et al. Maximal estimated cardiorespiratory fitness, cardiometabolic risk factors, and metabolic syndrome in the aerobics center longitudinal study. Mayo Clinic Proc. 2013;88:259-270.

15. Grundy SM et al. Implications of recent clinical trials for the National Cholesterol Education Program Adult Treatment Panel III guidelines. Circulation. 2004 Jul 13;110(2):227-39.

16. Silva AO, Tibana RA, Karnikowski MG, et al. Inflammatory status in older women with and without metabolic syndrome: is there a correlation with risk factors? Clin Interv Aging. 2013;8:361-367.

17. Sociedade Brasileira de Cardiologia. VI Brazilian guidelines on hypertension. Arq Bras Cardiol. 2010;95:1-51.

18. Rikli RE, Jones J. The senior fitness test. Defining functional fitness parameters. In: Senior Fitness Test Manual 2001. Champaign, IL: Human Kinetics; 2001.

19. Heyward VH. Assessing flexibility. In Heyward, VH. Advanced fitness assessment 2010. Champaign, IL: Human Kinetics; 2010.

20. ATS. ATS statement: guidelines for the six-minute walk test. Am J Respir Crit Care Med. 2002;166:111-117.

21. Santana MG, de Lira CA, Passos GS, et al. Is the six-minute walk test appropriate for detecting changes in cardiorespiratory fitness in healthy elderly men? J Sci Med Sport. 2012;15:259-265.

22. Ploutz-Snyder LL, Giamis EL. Orientation and familiarization to 1 RM strength testing in old and young women. J Strength Cond Res. 2001;15: 519-523.

23. Brown LE, Weir JP. ASEP procedures recommendation: accurate assessment of muscular strength and power. J Exerc Physiolonline. $2001 ; 4: 1-21$.

24. Prestes J, Tibana RA. Muscular static strength test performance and health: Absolute or relative values? Rev Assoc Med Bras. 2013;59:308-309.

25. Farias DL, Teixeira TG, Madrid B, et al. Reliability of Vertical Jump Performance evaluated with contact mat in elderly women. Clin Physiol Funct Imag. 2013;33:288-292.

26. Vischer UM, Safar ME, Safar H, Iaria et al. Cardiometabolic determinants of mortality in a geriatric population: Is there a "reverse metabolic syndrome"? Diabetes Metab. 2009;35:108-114.

27. Cheng HT, Huang JW, Chiang CK, et al. Metabolic Syndrome and Insulin Resistance as Risk factors of development of chronic Kidney Disease and Rapid Decline in Renal Function in Elderly. J Clin Endocrinol Metab. 2012;97:1268-1276.

28. Cabrera MA, de Andrade SM, Mesas AE. A prospective study of risk factors for cardiovascular events among the elderly. Clin Interv Aging. 2012;7:463-468.

29. Cabrera MA, Gebara OC, Diament J. et al. Metabolic syndrome, abdominal obesity, and cardiovascular risk in elderly women. Int $J$ Cardiol. 2007;114:224-229. 
30. Stenholm S, Koster A, Alley DE, et al. Joint association of obesity and metabolic syndrome with incident mobility limitation in older men and women - results from the Health, Aging, and Body Composition study. J Gerontol A Biol Sci Med Sc. 2010;65:84-92.

31. Messier SP, Gutekunst DJ, Davis C, DeVita P. Weight loss reduces knee joint loads in overweight and obese older adults with knee osteoarthritis. Arthritis Rheum. 2005;52:2026-2032.

32. Bouchard DR, Langlois MF, Brochu M, Dionne IJ, et al. Metabolically healthy obese women and functional capacity. Metab Syndr Relat Disord. 2011;9:225-229.

33. Sayer AA, Syddall HE, Dennison EM, et al. Hertfordshire Cohort. Grip strength and the metabolic syndrome: findings from the Hertfordshire Cohort Study. QJM. 2007;100:707-713.

34. Sartorio A, Proietti M, Marinone PG, et al. Influence of gender, age and BMI on lower limb muscular power output in a large population of obese men and women. Int J Obes Relat Metab Disord. 2004;28:91-98.

35. Hanson ED, Srivatsan SR, Agrawal S, et al. Effects of strength training on physical function: influence of power, strength, and body composition. J Strength Cond Res. 2009;23:2627-2637.

36. Reid KF, Fielding RA. Skeletal muscle power: a critical determinant of physical functioning in older adults. Exerc Sports Sci Rev. 2012;40: 4-12.

37. Rantakokko M, Mänty M, Rantanen T. Mobility decline in old age. Exerc Sports Sci Rev. 2013;41:19-25.
38. Deschenes MR. Effects of aging on muscle fibre type and size. Sports Med. 2004;34:809-824.

39. Koistinen HA, Zierath JR. Regulation of glucose transport in human skeletal muscle. Ann Med. 2002;34:410-418.

40. Kelley DE, Goodpaster BH. Skeletal muscle triglyceride. An aspect of regional adiposity and insulin resistance. Diabetes Care. 2001;24:933-941

41. Reid KF, Naumova EN, Carabello RJ, et al. Lower extremity muscle mass predicts functional performance in mobility-limited elders. J Nutr Health Aging. 2008;12:493-498.

42. Kelley GA, Kelley KS. Impact of progressive resistance training on lipids and lipoproteins in adults: a meta-analysis of randomized controlled trials. Prevent Med. 2009;48:9-19.

43. Cornelissen VA, Fagard RH, Coeckelberghs E, Vanhees L. Impact of resistance training on blood pressure and other cardiovascular risk factors: a meta-analysis of randomized, controlled trials. Hypertension. 2011;58:950-958

44. Strasser B, Siebert U, Schobersberger W. Resistance training in the treatment of the metabolic syndrome: a systematic review and meta-analysis of the effect of resistance training on metabolic clustering in patients with abnormal glucose metabolism. Sports Med. 2010;40:397-415.

45. Tibana RA, Navalta J, Bottaro M, et al. Effects of eight weeks of resistance training on the risk factors of metabolic syndrome in overweight/ obese women - “A Pilot Study". Diabetol Metab Syndr. 2013;5:11.
Clinical Interventions in Aging

\section{Publish your work in this journal}

Clinical Interventions in Aging is an international, peer-reviewed journal focusing on evidence-based reports on the value or lack thereof of treatments intended to prevent or delay the onset of maladaptive correlates of aging in human beings. This journal is indexed on PubMed Central, MedLine, the American Chemical Society's 'Chemical Abstracts

\section{Dovepress}

Service' (CAS), Scopus and the Elsevier Bibliographic databases. The manuscript management system is completely online and includes a very quick and fair peer-review system, which is all easy to use. Visit http://www.dovepress.com/testimonials.php to read real quotes from published authors. 